\title{
A CONSTRUÇÃO DO DEBATE SOCIOLÓGICO NO BRASIL ${ }^{1}$
}

\author{
Elide Rugai Bastos*
}

Quando entre cientistas sociais nos referimos ao termo construção imediatamente inferimos que se trata de um processo que se estende ao longo de um tempo ou período e num definido espaço, mobilizando diferentes atores ou agentes. Mais ainda, entendemos que esse processo compreende diferentes dimensões e tratamos de mobilizar algumas delas, entre as quais destacamos a econômica, a social, a política e a cultural.

É a partir dessa perspectiva que retomo aqui a problemática da formação da disciplina Sociologia no Brasil, buscando não estabelecer um salto entre a produção dos autores anteriores a 1930, usualmente denominados "intérpretes do país" lembrando que esse decênio constitui-se em momento privilegiado no processo de sistematização e institucionalização dessa área. Refirome, assim, a dois aspectos desse processo de construção - de um lado a sistematização do pensamento sociológico e de outro a institucionalização da sociologia - aspectos que se desenvolvem de forma articulada.

Primeiramente lembro os caminhos da sistematização. Antonio Cândido no livro "Formação da literatura brasileira" (1981) mostra que os diversos passos que levam à sistematização de

\footnotetext{
1 Aula Inaugural Programa de Pós-graduação em Sociologia Unicamp, proferida em 13 de março de 2013 no Instituto de Filosofia e Ciências Humanas da Unicamp.

* Professora do departamento de Sociologia da Unicamp.
} 
nossa literatura se estendem por longo período, compreendendo o que chamou de manifestações literárias até chegar à sistematização dessa literatura: a presença de temas comuns aos autores, de uma língua brasileira e de um público leitor. $\mathrm{O}$ argumento central do texto é o estabelecimento de uma linha de constituição, onde os elementos autor-obra-público em interação dinâmica operam como um triângulo explicativo do processo de sistematização da literatura brasileira, processo esse que explicita a continuidade de uma tradição de pensamento. Isto é, embora haja uma separação estética entre as diferentes escolas a vocação histórica as aproxima, o que cimenta a unidade sistemática entre essas diferentes expressões. Assim, a ideia de formação ganha centralidade como método que articula os aspectos estético e histórico.

Esse instrumento permite que o autor mostre como existe um interesse básico na literatura brasileira referido aos períodos que analisa; isto é, trata-se de uma literatura voltada para a construção de uma cultura válida no país, uma cultura nacional. "Quem escreve, contribui e se inscreve num processo histórico de elaboração nacional." (Candido, 1981, p.18) É certo que essa produção literária está perpassada pela questão das influências estrangeiras e ainda da dialética entre o cosmopolitismo e o localismo, questões que estão fortemente articuladas à proposta original.

Coloco aqui a questão: Esse método pode ser estendido para a análise do pensamento social brasileiro em geral? Ou para a sociologia brasileira, em particular? Creio que sim, o que já foi feito em vários trabalhos.

Como, pois pensar esse processo de constituição da sociologia brasileira? Ou mais amplamente do debate sociológico? Comecemos pela temática: existe um tema privilegiado nas análises sobre o social no Brasil que atravessa os diferentes períodos?

Creio que simplificando a resposta podemos dizer que a grande indagação presente nos vários momentos de desenvolvimento do pensamento social brasileiro diz respeito à questão do atraso. Porque uso a palavra atraso? Não só porque esse termo aparece explicitamente em muitas das abordagens 
dos autores, como porque está implícito em quase a totalidade dos textos, mesmo com outra denominação. As temáticas da modernização, os debates sobre o subdesenvolvimento, mas também as mais gerais como a pobreza, o analfabetismo, as diferenças regionais, ilustram bem a questão.

Para refletir sobre esses problemas, diferentemente das sociedades metropolitanas, centrais, as sociedades periféricas como o Brasil acabam, a maior parte das vezes, por refletir as ideias produzidas fora delas e aplicá-las a uma realidade que nem sempre as comporta plenamente. Ou seja, as explicações são transferidas para uma sociedade onde, se não são ausentes, pelo menos são exíguos os portadores sociais para as mesmas, o que dificulta sua legitimação. Essa adaptação e esse deslocamento alteram tanto a função das ideias como o papel dos intelectuais. As ideias operam como forças sociais e os intelectuais, nessas sociedades assumem um grande protagonismo político o que torna necessário explicálo. Assim, as características da sociedade brasileira nos obrigam a pensar num mesmo movimento a estrutura da sociedade, os problemas que a atravessam e as ideias que interpretam tanto a sociedade como esses problemas, pois estas servem de suporte à institucionalização das medidas que visam o funcionamento político e social. Não é sem sentido que entre nós coube às Ciências Sociais a produção de uma narrativa e uma interpretação do país que ao mesmo tempo ancora discursos, medidas institucionais, comportamentos políticos e o senso comum que fundam a cultura política. É por isso que o estudo sobre os intelectuais e sua interpretação do país é elemento constitutivo da reflexão sociológica brasileira. Mais, o diálogo entre as diferentes interpretações é componente fundamental da busca das explicações sobre o país.

Inúmeros autores, desde o século XIX são desafiados a pensar sobre esses problemas. Qual ou quais os traços que nos afastam das sociedades ditas "adiantadas"? Essa questão foi respondida através de diagnósticos diferentes, mas que em geral indicavam pontos comuns: a escravidão, os resquícios coloniais, a questão agrária, etc. Para exemplificar lembro um questionário enviado pelo regente D. João, em 1807, portanto antes da transferência da 
Corte para o Brasil. São perguntas endereçadas aos agricultores, isto é, àqueles proprietários dos empreendimentos agrícolas sobre sua opinião a respeito dos obstáculos que impediam a modernização da economia e da sociedade brasileira. Alguns desses depoimentos são notáveis. Pelo que conheço é um dos primeiros trabalhos de interpretação do país. Destaco a resposta de Rodrigues de Brito que entre outros problemas aponta a situação subordinada da mulher na sociedade, que segundo ele se transformava em impedimento a que esse setor da população pudesse constituir-se em mão-de-obra produtiva à economia da colônia. (Brito, 2004)

Mas se temas e dilemas convergem, esses autores contam com um reduzido instrumental analítico para a abordagem das questões sociais. Em outros termos, não existe um discurso específico que permita a convergência dos diálogos e mesmo o contraponto com outras sociedades e seus analistas.

Essa situação se altera partir dos anos 1920, com a crise do pacto oligárquico que impele os intelectuais ao diálogo sobre as razões da crise. Assim, discutem-se problemas da adequação das instituições vigentes ao perfil da sociedade brasileira, o transplante de ideias, costumes, comportamentos, etc. Nesse quadro vários movimentos, com características muitas vezes diversas, emergem: falo da mobilização católica em torno do Centro D.Vital, da revista "A Ordem", da semana de Arte Moderna e outros movimentos modernistas em vários pontos do país, do debate comemorativo dos 100 anos da independência entre intelectuais e políticos que faz um balanço sobre os rumos da República - que podemos acompanhar através do livro de Vicente Licínio Cardoso "À Margem da História da República"-, do movimento regionalista do Nordeste liderado por Gilberto Freyre, entre outros. Lembro ainda do projeto não completado de Oliveira Vianna de um estudo regionalista, cujos primeiros resultados aparecem em "Populações Meridionais do Brasil".

Mas será no decênio de 1930 que o processo de sistematização do pensamento sociológico avança, pois as explicações fundadas na sociobiologia e no determinismo geográfico, que servem de suporte para as explicações anteriores, serão questionadas. Nesse 
movimento a figura de Gilberto Freyre será fundamental; em "Casa-grande \& senzala" argumentará na direção de demonstrar a anticientificidade das afirmações sobre a inferioridade ou superioridade racial, e da restrição à consideração das formas sociais e culturais desenvolvidas nos trópicos como civilizadas. É possível afirmar-se que o movimento de constituição do discurso sociológico na bibliografia brasileira tem seu momento privilegiado nesse período. Trata-se da linguagem, um dos elementos apontados por Antonio Candido como constitutivo do processo de sistematização.

O terceiro ponto apontado pelo autor "um conjunto de receptores, formando os diferentes tipos de público, sem os quais a obra não vive" no caso da sociologia se define mais claramente após 1930, e coincide, em alguns pontos com a institucionalização dessa disciplina.

Passo rapidamente ao processo de institucionalização das ciências sociais que compreende, naturalmente, o da sociologia. Quero enfatizar que não existe uma ruptura de fato na consideração da importância das análises anteriores, nas o contexto de transformação do caminho trilhado está associado às transformações políticas e institucionais desencadeadas pela denominada Revolução de 30 . Nesse cenário a Sociologia vai tornar-se disciplina acadêmica, absorvendo as mudanças impostas por esse estatuto. Entre estas lembro a centralização da política educacional, a ênfase na formação dos professores para o curso primário, o surgimento de novas editoras, o lançamento de algumas coleções de livros de interpretação do país.

Sabemos que a institucionalização dos cursos de Ciências Sociais no país se dá, primeiramente na década de 1930, com a criação dos da Escola de Sociologia e Política, em 1933, da Universidade de São Paulo, em 1934, ambos na cidade de São Paulo e o da Universidade do Distrito Federal, em 1935, no Rio de Janeiro. Este último foi fechado com a extinção da UDF no início do Estado Novo, ressurgiu, inicialmente com outras características, na Universidade do Brasil, em 1939.

Também, é conhecido o fato desses cursos terem sido formados a partir da contratação de muitos professores 
estrangeiros - por exemplo, a denominada missão francesa na USP, os professores americanos de Antropologia e Sociologia, na ESP.

Embora se possa falar de pesquisas importantes e publicações nos primeiros anos de atuação desses cursos - por exemplo, a revista "Sociologia", publicada pela Escola de Sociologia e Política é de 1939 - os primeiros alunos que passam a atuar como professores na área se consolida como conjunto na segunda metade da década de 1940.

Não por acaso é esse o momento imediatamente posterior à Segunda Guerra Mundial. Trata-se, sem dúvida, de um período marcado pela crise - ou pelas crises - uma vez que não só é necessária a reconstrução material dos elementos que compõem as esferas econômica, política, social e cultural, como se configura uma tarefa áspera: Fazer um balanço das causas que levaram à barbárie, barbárie relacionada à própria questão do humanismo e, ainda, refletir sobre as formas de evitar-se uma nova queda. Naturalmente, trata-se de uma avaliação sobre a crise nos seus vários momentos, anteriores e posteriores.

Hannah Arendt, afirma que uma crise nos obriga a voltar às "velhas" questões e fazer dela mesma uma experiência e oportunidade de reflexão. Exige respostas novas ou velhas, mas, de qualquer modo, julgamentos diretos. Trata-se de um momento de grande importância na circunscrição e na ampliação do papel do intelectual, quando se coloca o perigo representado pela naturalização do conflito social e a consequente indiferença em relação ao sofrimento humano. Se isso ocorrer perde-se o senso crítico e essa perda traz um esvaziamento da substância constitutiva da atividade intelectual. Ilustram bem o período pós Segunda Guerra Mundial Jean-Paul Sartre editando a revista "Temps Modernes" e Elio Vittorini, com a publicação de "Il Politécnico". Essas propostas se pautam por grande amplitude, pois não pressupõe apenas atuar na direção de mudanças nas condições materiais, mas de operar uma espécie de reforma moral referida à emancipação do homem. Pode-se dizer que se trata de um programa dos intelectuais europeus do pós-guerra que busca 
resgatar os princípios iluministas esquecidos durante o período nazi-fascista. Poderia dar mais exemplos da retomada da questão sobre o compromisso do intelectual, mas creio que estes exemplos já são suficientes para continuar desenvolvendo a temática que proponho. As preocupações dos intelectuais europeus que viveram a guerra e em muitos casos, lutaram contra o nazismo e o fascismo como "partisans", traziam para todos a necessidade de pensar o mundo, de sair da torre de marfim, de olhar além das suas limitadas fronteiras pessoais, comunitárias ou nacionais.(Bastos e Rêgo, 1999, pp. 7-41)

Nos anos 1950, essas questões levam à fundação de organizações internacionais, reunindo intelectuais e políticos, que abrigaram aqueles objetivos e que passaram a se preocupar com a miséria no mundo. Um dos mais fortes exemplos é o da atuação da UNESCO, agência da Organização das Nações Unidas - ONU. A área do conhecimento que ganhou força no sentido de denunciar, diagnosticar, analisar as causas da miséria e da fome, foi a área das Ciências Sociais, na qual a Sociologia assume destaque.

Assim, o grande tema da sociologia, tanto no plano mundial como no nacional é o da mudança social, assunto que alcançou importância dentro e fora dos meios acadêmicos. Nos anos 1950 a Sociologia se tornou linguagem privilegiada para a percepção das transformações ocorridas. Nesse momento, no Brasil três sociólogos, pertencentes a diferentes tradições teóricas, lideravam grupos dedicados ao debate não só dessa temática, mas sobre o papel do sociólogo no processo de mudança provocada. No Rio de Janeiro Luiz Aguiar Costa Pinto e Guerreiro Ramos; em São Paulo, Florestan Fernandes. (Villas Boas, 2006) No I Congresso Brasileiro de Sociologia, promovido pela Sociedade Brasileira de Sociologia em 1953, as posições diferentes, principalmente entre Guerreiro Ramos e Florestan Fernandes aparecem explicitadas. A oposição entre ambos refere-se basicamente à denúncia de Florestan Fernandes ao processo uniforme de desenvolvimento que se aplica ao Brasil, desconhecendo-se que estamos diante de uma sociedade ou um sistema interligado entre partes, resultando que a absorção das medidas aplicadas se dá de forma desigual e combinada. Para 
Guerreiro Ramos, membro do ISEB, a combinação da política que entende basicamente como a ação do Estado - e da ciência garantiria um processo de desenvolvimento homogêneo, benéfico a toda a população.

Costa Pinto, dirigindo então o Centro Latino-americano de Pesquisas em Ciências Sociais, realiza em 1959 um seminário sobre resistências e obstáculos à mudança, colocando em debate ideias de intelectuais de vários países, apresentando interpretações em oposição. O diagnóstico de Costa Pinto, por exemplo, enfatiza os conflitos decorrentes da coexistência de duas ordens sociais - a "antiga" e a "nova" (Villas Boas, 2006, p. 76). Florestan Fernandes, embora salientando a importância do debate, não concorda com essa tese, explicitada na afirmação de Jacques Lambert sobre a existência de dois Brasis. Nas várias versões do livro "Mudanças Sociais no Brasil", primeiramente publicado em 1960, refundido em 1974, revisto em 1979, lembra como a modernização se dá e se alimenta a partir da permanência do "tradicional"; as novas formas se nutrem das antigas. (Fernandes, 1974).

Assim, os debates da sociologia, nessa fase, desde 1958 até meados dos anos 60 estão associados a um movimento mais amplo que abarca preocupações comuns aos intelectuais dos países latino-americanos, bem como a iniciativas de diversos organismos internacionais que propiciam o debate comum dos problemas. Ilustram esse caminho e mostram o resultado dessas reflexões várias revistas lançadas nesse período: América Latina, no Rio de Janeiro, 1958; Revista Brasileira de Ciências Sociais, em Belo Horizonte, 1961; Ciencias Sociales: notas y info rmaciones, da Unión Panamericana, Washington, 1950; Revista de ciencias sociales, da Universidad Rio Pedras, em Porto Rico, 1957; Revista de ciencias sociales, na Costa Rica, 1956; Tiers monde, do Institut d'études du developpement economique et social de l'Université de Paris, 1960; Latin American Research Review, da Latin American Studies Association, em Austin, 1965; Estudos Sociais, no Rio de 
Janeiro, $1958^{2}$. Isso sem esquecer os livros, relatórios e anais de encontros editados no período.

A Sociologia, nesse debate, ganha um lugar especial por várias razões. O estabelecimento do âmbito e das tarefas da Sociologia procura responder à formulação, presentenas sociedades latino-americanas, sobre a necessidade de planejamento do desenvolvimento. Comentando em 1967 o livro de Celso Furtado "Subdesenvolvimento e Estagnação na América Latina", Simon Schwartzman (Schwartzman, 1967) lembra que as reflexões do autor - apresentando a tese de que o desenvolvimento espontâneo, depois da fase de substituição das importações não é mais possível e colocando como central a necessidade do planejamento -, são antes devedoras à sociologia política do que à economia.

Sendo o planejamento visto como tarefa não apenas técnica, mas política, envolvendo mudanças sociais, configura-se a tarefa de refletir sobre as articulações entre o Estado e a Sociedade, aquele encaminhando as necessidades, aspirações e reivindicações desta. Naturalmente, a noção supõe a participação ativa dos intelectuais no processo, pois o que estaria em questão seriam os movimentos políticos capazes de alterar as bases das estruturas de poder. Ora, o passo seguinte para a definição desse objetivo é o diagnóstico dos fatores estruturais que impedem o desenvolvimento. Aponta para um movimento de especialização da Sociologia e da Ciência Política, que possibilitaria o aprofundamento das pesquisas, indicando que o problema reside na quase ausência de comunicação entre essas especialidades. Assim, essas disciplinas poderiam assumir a investigação voltada ao diagnóstico, aprofundando "o estudo do que está ocorrendo no continente, sem chegar necessariamente a conclusões, mas pelo menos equacionando os problemas existentes. (...) Estamos em um momento em que é necessário mudar os

\footnotetext{
${ }^{2}$ Refiro-me a periódicos cuja publicação foi iniciada nesse período. Várias outras revistas haviam se firmado como importantes nas décadas anteriores, por exemplo: Sociologia (São Paulo, 1939); Revista Mexicana de Sociologia (México, 1939); Boletín del Instituto Sociología (Buenos Aires, 1942); a coleção Cuadernos de Sociologia (México, 1947).
} 
supostos, discutir o 'evidente', e estabelecer a comunicação e o diálogo entre as especialidades." (idem: 6)

Se o período ditatorial fez calar por momentos certo debate intelectual, voltou-se pouco a pouco a certos temas. Naturalmente falar sobre os temas desenvolvidos nas Ciências Sociais nos anos 1970 e 80 é tarefa muito ampla. Lembrarei como, de modo geral, eles foram se alternando no desenrolar dos anos.

Nos anos 1970 encontramos uma grande produção sobre a questão agrária, pois diante da censura política o tema apresentavase como uma das formas de denuncia das assimetrias presentes na sociedade. Em outras palavras, as políticas do governo militar voltadas à modernização e à ocupação territorial, ambas não descoladas das medidas de segurança adotadas, remetem diretamente às temáticas rural e agrária. Um dos eixos importantes da discussão, em grande parte acionado por um documento da CEPAL de $1966^{3}$ é o das populações marginais. Sem entrar agora no debate que o próprio termo marginalidade provocou, sendo posteriormente substituído por exclusão ou pela formulação mais ampla sobre o processo de excludência, lembro que a discussão sobre "arcaico" e "moderno", tão presente nas reflexões anteriores decorre dessa definição.

É nesse quadro que, por exemplo, se encaixou a visão do "rural como atrasado", como "obstáculo ao desenvolvimento", que conduz várias pesquisas e justifica vários artigos. A grande pesquisa do Comitê Interamericano de Desenvolvimento Agrícola - CIDA - , sobre Posse e uso da terra e desenvolvimento socioeconômico do setor agrícola, publicada em 1966, tem ampla divulgação na América Latina.

Nos anos 1970 e início dos 80 essa questão ganha outra dimensão. Passa-se a discutir a importância desses atores sociais e dos movimentos sociais que ocorrem no setor agrário como

${ }^{3} \mathrm{O}$ documento da CEPAL, muito debatido no período propõe a definição de marginalidade em três níveis: marginalidade radical, marginalidade por desajustamento e marginalidade em geral. Vide Luiz Pereira, 1971, pp. 159178. 
fundamentais para uma nova discussão sobre a política. O encontro das disciplinas - Antropologia, Sociologia, Política e História redefinem o modo pelo qual se analisa a situação social, tanto no campo como na cidade.

Alguns passos da nova definição dos problemas urbanos já haviam sido dados na década de 1960. Exemplifico com os artigos de Richard Morse, Cidades Latino-Americanas: aspectos da função e estrutura e de Milton Santos, As grandes cidades Latino-Americanas, ambos na revista América Latina ${ }^{4}$.Esses dois autores continuaram suas reflexões no período posterior, enfocando novos aspectos da questão.

É importante lembrar as discussões sobre o papel do Estado, sobre os novos atores dos movimentos sociais, entre os quais se mostrava o peso da classe média urbana, debate que fazia parte das denúncias às restrições democráticas durante o período ditatorial.

Pós-abertura política, a partir de meados dos anos 1980, ganha força, também graças a um movimento internacional em torno da questão dos direitos, a reflexão sobre a questão democrática, não mais centrada apenas na questão da desigualdade, mas compreendendo, também a questão da diversidade. Volta-se ao estudo da vida privada, da identidade. Constata-se, naturalmente, o perigo de uma visão fragmentada da sociedade se os dois elementos não forem colocados em discussão de modo simultâneo. Nesse processo se redefine a questão nacional - resumindo, a discussão da necessidade/possibilidade de superposição das fronteiras da sociedade e do Estado. Em outros termos, a sociologia retoma sob outra ótica a questão da representação de todos os setores da população.

Temas culturais e políticos ganham espaço: diferenças culturais, respeito pelos direitos compreendidos nas fronteiras da cultura versus direitos universais, políticas sociais e políticas culturais, inclusão social, transformações do trabalho, questão de gênero, como atenuar os resultados negativos da exclusão histórica de vastos setores da sociedade.

${ }^{4}$ Respectivamente: Ano V, no 3, 1962, pp. 35-64 e Ano 6, no, pp. 85-90. 
O mundo abre para as Ciências Sociais novos temas. Porém, outra vez, nos países onde a questão democrática chega com atraso - por exemplo o Brasil, países latino-americanos, países africanos - por vários motivos - colonialismo, escravidão e independência e abolição tardias - os desafios à reflexão são maiores. Por isso as tarefas da nova geração de cientistas sociais que agora está se formando é ampla, importante, necessariamente criativa e deve ter por base o conhecimento, a competência e principalmente o compromisso social e político. Ser cientista social hoje, como sempre, requer um incorformismo face às injustiças do mundo e o empenho com sua superação.

\section{Bibliografia}

BASTOS. E.R e RÊGO. W.D.L. Intelectuais e política: a moralidade do compromisso. São Paulo: Olho Dágua, 1999.

"A Sociologia e a circulação de idéias". In: Linhagens do pensamento político-social no Brasil, Projeto Temático, 1ํo relatório. São Paulo: FAPESP/CEDEC, 2009, pp. 300-314.

CANDIDO. A. Formação da literatura brasileira. 6 $6^{\mathrm{a}}$ Ed., Belo Horizonte: Itatiaia, 1981.

CHARTTERJEE. P. The Nations and its Fragments. Princeton: Princeton University Press, 1993.

COSTA PINTO. L.A. "Panorama geral”. In: COSTA PINTO. L.A e CARNEIRO. E. As Ciências Sociais no Brasil. Rio de Janeiro: CAPES, Série Estudos e Ensaios - 6 - 1955, pp.7-72.

"Introdução". In: Anais do Seminário Internacional Resistências às Mudanças - fatores que impedem ou dificultam o desenvolvimento. Rio de Janeiro: Centro Latino-Americano de Pesquisas em Ciências Sociais, 1960, publicação nº 10, pp. 5-11. 
FERNANDES. F. Mudanças sociais no Brasil. São Paulo: Difusão Européia do Livro, 1974.

- A Sociologia no Brasil. Petrópolis: Vazes, 1977.

. A condição de sociólogo. São Paulo: Hucitec, 1978.

- A Sociologia numa era de revolução social. São Paulo: Nacional, 2 ${ }^{\mathrm{a}}$ ed., 1976.

IANNI. O. Sociologia da Sociologia. $3^{\mathfrak{a}}$ ed. São Paulo: Ática, 1989.

Sociologia da Sociologia latino-americana. Rio de Janeiro: Civilização Brasileira, 1971.

LIEDKE. E. F. "Sociologia brasileira: tendências institucionais e epistemológico-teóricas contemporâneas". Sociologias, Porto Alegre, ano 5, no 9, jan./jun. 2003, pp. 216-245.

LIPPI OLIVEIRA. L. “Diálogos intermitentes: relações entre Brasil e América Latina". Sociologias, Porto Alegre, ano 7, nº 14, jul./ dez. 2005. Scielo.

MAIO, M. C,.VILLAS BÔAS, G. (orgs.). Idéias de modernidade e Sociologia no Brasil. Ensaios sobre Luiz de Aguiar Costa Pinto. Porto Alegre: Editora UFRGS, 1999.

NOBRE. M. "Luta por reconhecimento: Axel Honneth e a Teoria Crítica". In: Axel HONNETH. Luta por reconhecimento. A gramática moral dos conflitos sociais. São Paulo: Editora 34, 2003, pp.7-19

PEREIRA. L. Ensaios de Sociologia do Desenvolvimento. São Paulo: Pioneira, 1970.

. Ensaios sobre o Brasil contemporâneo. São Paulo: Pioneira, 1971.

RODRIGUES DE BRITO. J. Cartas econômico-políticas sobre a agriculturae comércio da Bahia. [1807]. Série FIEB-Documentos Históricos. Salvador: FIEB, 2004. 
$|300|$

Seção Especial

SCHWARTZMAN. S. "Subdesenvolvimento, revolução e Ideologia". Originalmente em Revista Latinoamericna de Sociologia. $\mathrm{n}^{\mathrm{o}} 1,1967$. (site schwartzman)

VILLAS BOAS. G. Mudança Provocada. Passado e futuro no pensamento sociológico brasileiro. Rio de Janeiro, Editora FGV, 2006. 